\title{
The economic analysis of product substitutability and in- timidation effect on vertical integration
}

\author{
Yu-Chieh Chang ${ }^{1 *}$, Shu-Yi Liao ${ }^{2}$ \\ ${ }^{1,2}$ Department of Applied Economics, National Chung Hsing University, Taichung, Taiwan
}

\author{
Keywords \\ Downstream R\&D \\ Vertical integration \\ Product substitutability \\ Intimidation effect \\ Economic effect \\ Received: 14 March 2019 \\ Accepted: 12 June 2019 \\ Published: 26 August 2019
}

\begin{abstract}
This study aimed to analyze and compare the economic efficiency of the separation model and vertical integration model. For the industry of downstream Research and Development (R\&D), this model examines the effect of market size and product substitutability on the economic output. This study applied the modified Cournot duopoly model proposed by Buehler and Schmutzler (2008) and Milliou and Pavlou (2013). This study establishes the following results: (i) the benefits of a downstream firm on vertical integration will increase when the product substitutability is lower. (ii) While the market size becomes bigger, the benefit has further enhanced this conclusion. The integration firm will promote investment in R\&D to cause intimidation effect. (iii) When the product substitutability is higher to a certain degree, the benefits will also increase. Thus, a high degree of product homogeneity and a high degree of product heterogeneity is more suitable for vertical integration. In the long run, the industry that will extend or increase demand suggests a merger as early as possible. These findings imply that in the long run, the early adoption of M\&A strategies will lead to better economic benefits to firms from such industries as will see the scale expansion and more demands in the future; it also can help firms to make consideration and planning in advance for whether to expand the scale.
\end{abstract}

(C) 2019 The Author(s). Published by TAF Publishing.

\section{INTRODUCTION}

Since the end of the 20th century, enterprises have been experiencing Merger and Acquisition (M\&A), and after a long time of experience accumulation, $M \& A$ is found to be beneficial to the growth of companies. In the past decade, especially due to the deepening of globalization, many large enterprises that have accumulated large amounts of wealth tried to expand their territory through M\&A. The statistical data from the Institute for Mergers, Acquisitions and Alliances (IMAA) show that the number and scale of M\&A between global enterprises continue to increase.

In recent years, there have been numerous M\&A cases, including the consolidations between major international major companies and those between local enterprises. Some M\&A cases in recent years are as follows: Volkswagen acquired Porsche and YFY merged with Chung Hwa Pulp Corporation in 2012; Avago acquired Broadcom, Intel acquired the chip designer Altera and Tsinghua Unigroup ac- quired Powertech (the world's largest memory assembly and testing company) in 2015; Foxconn acquired Sharp and the American wireless telecommunication provider AT\&T acquired Time Warner in 2016; Wal-Mart acquired a newly founded e-commerce company Jet.com in 2016 and then acquired the vertical footwear e-commerce company ShoeBuy in 2017. In the apparel sector, the upstream down material cleaning company KWONG LUNG integrated the downstream apparel firm Quang Viet to expand its production lines and reduce costs. Eink and Sony Corporation established a joint venture Linfiny.

According to Hamel and Getz (2008), M\&A is nothing but a business expansion, and the real growth must originate from innovation, and the latter comes from R\&D. Today, new products come to market faster than R\&D, and the innovative $R \& D$ cost and failure rate are very high. For firms, it will be much convenient and time-saving if they can directly purchase the patented technologies which have been

\footnotetext{
*corresponding author: Yu-Chieh Chang

†email: deliacyc@hotmail.com
} 
researched and developed; and such a strategy can also provide an important thinking direction for a large amount of capital accumulated by enterprises and their transformation and development in the future. The modern M\&A is not just business expansion but considering the technologies from the innovative R\&D in order to ensure the production capacity and improve the bargaining advantage, therefore pursing the profit maximization. So, it is more necessary to establish the self-own industrial characteristics (namely the core competitiveness) so as to realize the maximum comprehensive benefits of M\&A, especially for the industries based on the key technologies, such as semiconductor, panel and other consumer electronics.

The M\&A cases mentioned above include both horizontal and vertical integration. However, this study aims to explore the economic benefits of vertical integration to firms and even the industry as a whole. Therefore, the following discussion will focus on the vertical integration to explore the influence of R\&D innovation and product substitutability on the vertical integration benefits.

For the researches related to vertical integration, the foreign researchers, such as Buehler and Schmutzler (2005), Buehler and Schmutzler (2008), Hart, Tirole, Carlton, and Williamson (1990), Ordover, Saloner, and Salop (1990), Y. Chen (2001), based on the Cournot duopoly model to establish the modified theoretical model for vertical integration. The results show that vertical integration can lead to competitive advantages and profits by reducing costs or increasing the costs of competitors, which provides valuable references for M\&A decisions.

Turning to the local researches, most researchers conducted the quantitative analysis through collecting the business operation data (such as financial statements), and then summarized their benefits or influencing factors (Al-Barashdi, 2016; Y. C. Chen, 2014; J. R. Lin, Hsieh, Hsu, Huang, \& Liu, 2010; S. H. Lin, 2013; Piyachat, 2017; Silva \& Madushani, 2017; Sun, 2000). Some researchers utilized he case study or event study to analyze the benefits of individual enterprise or industry (C. Y. Lin, 2010; Yang, 2013). The above researches failed to provide a reliable logical thinking framework for the decision and implementation of the M\&A strategy.

This study is based on the theoretical model created by Buehler and Schmutzler (2008) and Milliou and Pavlou (2013) and mainly discusses the impact of product substitutability on the overall benefits as well as whether the ver- tical integration can result in an intimidation effect ${ }^{1}$, and then analyze the implications of this study results on the enterprises' M\&A strategies; finally, the conclusion will be presented with the recent M\&A cases as pieces of evidences. This study aims to establish a logical theoretical framework for this topic, and give some directional references to firms when they are making decisions, such as "Is the integration necessary? Will the integration help firms increase profits?" "Can we increase our market share?" and "Is there any need for expansion of the factory?".

\section{LITERATURE REVIEW}

The concept of vertical integration was first presented by Coase (1937). It mainly describes the vertical integration as a process where the firms make the transaction an internal action by adjusting their own enterprise structures, and implement the input and output by themselves so as to replace the transaction in the open market. For example, in 1993, Merck\&Co acquired a downstream company Medco Containment Services which is the largest medical service distributor of USA; moreover, America Online (AOL) merged with an upstream company Time Warner, and established a new company AOL Time Warne in 2000.

Among the researches supporting the vertical integration strategies, Greenhut and Ohta (1979) used the successive oligopoly model and assumed the Cournot quantity competition between the upstream and downstream firms to compare the price changes of Intermediate and final goods when there is vertical integration and there is not. Salinger (1988) went further than Greenhut and Ohta (1979) to discuss the price changes of intermediate and final goods when the number of vertical integrations within a certain industry increase.

Salinger (1988) also used the Cournot duopoly model and found that when there is only one firm engaged in R\&D of process innovation, the increase in the number of firms will reduce the R\&D motivation of such R\&D firm. Milliou (2004) assumed an R\&D intensive industry which has a monopolistic upstream market and an oligopolistic downstream market, and mainly discussed how the degree of information flow between the upstream and downstream firms which have completed the vertical integration would affect their competitors experiencing no vertical integration. The results show the information flow mainly originates from the monopolistic upstream firm; therefore, the downstream firm that firstly integrates with the upstream

$1 \quad$ Buehler and Schmutzler (2008) indicated that the vertical integration between upstream and downstream will result in an intimidation effect on competitors. After integration, firms will increase R\&D investment and reduce competitors' R\&D investment. The vertical integration itself can reduce the marginal cost and generate more profits due to R\&D investment. 
firm will be in a good position to obtain the R\&D confidential of competitors.

J. R. Lin et al. (2010) collected 247 sample companies which announced M\&A from 1992 to 2008, and then screened the same according to sample attributes and acquisition of the related financial information to select those which are listed or traded OTC in Taiwan and remain listed or traded OTC after M\&A, therefore obtaining 97 valid samples. The innovation activities were measured in terms of input (R\&D amount, R\&D personnel and R\&D expenditure) and output (number of patents, technology improvement and new product development) to estimate the impact of M\&A and R\&D input on patent output. The results show that the R\&D stock and the weighted patent rights showed significant positive benefits, indicating that Taiwan companies should, after M\&A, pay more attention to R\&D input, thereby improving the patent performance.

Huang (2008) assumed an industry composed of the oligopoly upstream side and oligopoly downstream side, and then took the perspective of the downstream company A to explore whether the upward vertical integration would generate more profits than the horizontal integration between downstream companies or not. The results show this company would obtain more profits through vertical integration than horizontal integration.

$\mathrm{Li}$ (2008) also assumed an oligopoly industry where the upstream market is composed of four firms with R\&D and the downstream market comprises two firms without R\&D, and then explored whether the downward vertical integration or the horizontal integration within the upstream market would generate more profits for the upstream firm A. The results show the downward vertical integration will generate more profits than the horizontal integration within the upstream market, and such profit difference will expand with the increase in market demand. Therefore, the upstream firms are inclined to adopt the vertical integration strategy for market entry. After that, as the upstream firms see a decreasing R\&D marginal return, the production cost will increase. In this case, a stronger monopolistic firm will remain good position, because there is no need yet for this firm to quickly respond in terms of output and price; and after the vertical integration, the downstream firms facing more intensive competition will make quick response in output and price to address the increase in production cost. So, the higher the R\&D returns, the smaller the profit difference between horizontal and vertical integration.

\section{THE MODEL}

For an oligopoly industry featuring the homogeneous products, the competition will focus on the volume of production, as is the case with competition among oil producers. If the oligopoly firms produce differentiated products of the same kind, things will be different, for example, the competition among automakers mostly focuses on price. The factor product substitutability analyzed here refers to the differentiated products of the same kind, so this study adopts the price competition in the Cournot model.

\section{Overview}

Therefore, this study is based on the Cournot model established by Buehler and Schmutzler (2008) and Milliou and Pavlou (2013) to modify the linear Cournot oligopoly competition model and assumes the existence of upstream R\&D to deduce and compare the economic benefits to the downstream firms after M\&A. The Cournot model is a simple model considering only two oligopoly firms, so it is also called as duopoly model. Presented by the French economist Cournot in 1838, this model is the earliest version of the Nash equilibrium application. Cournot model is often taken as the starting point for the theoretical analysis of oligopoly, and its conclusion can be easily extended to the case of three or more oligopoly firms.

Buehler and Schmutzler (2008) established a model that discusses the vertical integration by the downstream companies conducting R\&D, and the results showed the R\&D expenditure of the firms engaged in vertical integration would have an intimidation effect on the R\&D expenditure of firms not doing so. Milliou and Pavlou (2013) presented a model which deals with the horizontal integration between the upstream firms conducting R\&D, and discusses the impact of a firm's product substitutability $(\gamma)$ on the vertical integration ${ }^{2}$. Since the product substitutability was not analyzed by Buehler and Schmutzler (2008), this study will consider how the product substitutability and intimidation will affect the industry where there is vertical integration by firms conducting R\&D.

The vertical integration model set by this study belongs to an asymmetric vertical integration model, which assumes an industry where the upstream side has relations with the downstream side and there are only two independent upstream firms $\left(U_{i}, i=1,2\right)$ and two independent downstream firms $(D i, i=1,2)$. Under separation, both upstream and downstream firms are Cournot competitors. To simplify this model, this study omits the fixed costs of two upstream firms $\left(U_{i}\right)$, and assumes they would sell the inter-

\footnotetext{
$\overline{2 \quad \text { Milliou and Pavlou (2013) }}$
} 
mediate goods (e.g., key parts) to the downstream firms at the Wholesale Price. To produce one unit of the final product, a downstream firm requires one unit of the intermediate good provided by an upstream firm. The cost of an intermediate good is $w_{i}(i=1,2)$.

Moreover, both two downstream firms $\left(D_{i}\right)$ are assumed to carry out the technical $\mathrm{R} \& \mathrm{D}\left(x_{i}, i=1,2\right)$ in order to reduce their manufacturing costs $\left(C_{D_{i}}, i=1,2\right)$. Since the products produced by downstream firms feature product substitutability $(\gamma)$, the larger the value of $\gamma(0 \leq \gamma \leq 1)$, namely the product substitutability, the smaller degree of product differentiation.

\section{Separation}

In this model, there are two mutually independent upstream firms $\left(U_{s_{1}}\right.$ and $\left.U_{s_{2}}\right)$ and two mutually independent downstream firms $\left(D_{s_{1}}\right.$ and $\left.D_{s_{2}}\right)$. Moreover, the downstream firms need to purchase one unit of key part in order to produce one unit of final product, which will be sold to the consumers in the end.

We assume in order to avoid technology outflow, the downstream firms cannot purchase intermediate goods from both upstream firms at the same time, so the downstream firms $D_{s_{1}}$ will only purchase intermediate goods from the upstream firm $U_{s_{1}}$. Similarly, $D_{s_{2}}$ will purchase intermediate goods from $U_{s_{2}}$. Finally, the final products will be manufactured and sold to consumers respectively. Please see Figure 1 for the situation without integration.

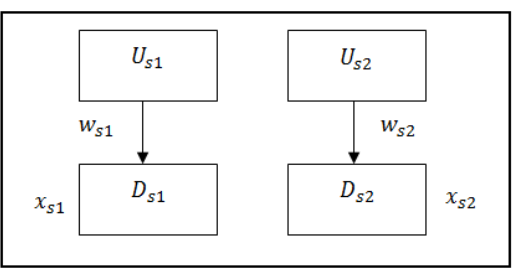

FIGURE 1. The situation without integration

This study will simulate strategies possibly to be carried out by firms: first, assume that the downstream firm $\left(D_{s i}\right)$ conducts R\&D, but the upstream firm does not; next, focus on one downstream firm $\left(D_{s_{1}}\right)$ to discuss whether to carry out the upward M\&A; finally, follow the competition mode between the downstream firms pursuing the maximum profit to deduce the strategic benefits. In the product market, firms face a linear inverse demand curve.

$$
p_{s i}=a-q_{s i}-\gamma q_{s j}
$$

with $i, j=1,2, i \neq j, 0 \leq \gamma \leq 1$

Where $p_{s i}$ is the price of downstream firms $D_{s i}$ and $q_{s i}, q_{s j}$ representative the outputs of downstream firms $a$ is market size which $a>0$. The parameter $\gamma$ is product substitutability.

Second, downstream firms decide about their cost-reducing investments. Both firms initially have identical transformation costs $\bar{t}>0$. Denoting firm $i^{\prime}$ s efficiency improvement by $x_{s i}$, then post transformation costs are $\bar{t}-x_{s i}$. Additionally, downstream firms use the price $w_{s i}$ to obtaining the input good from upstream. Therefore, downstream firms' marginal cost is thus given by

$$
C_{D s i}=\bar{t}-x_{s i}+w_{s i} i=1,2
$$

and the profit maximization for downstream firms $\pi_{D s i}$ can be expressed as

$$
\pi_{D s i}=\left(p_{s i}-c_{D s i}\right) q_{s i}-2 x_{s i}^{2}, i=1,2
$$

We assume $2 x_{s i}^{2}$ is the investment of research and development ${ }^{3}$. The investment of R\&D as affected by diminishing returns. Higher R\&D investment let production cost increase, then the profits will down. Third, the profits for upstream firms can be written as

$$
\pi_{U s i}=w_{s i} \times q_{s i}, i=1,2
$$

Now, substituting Equation (1) and Equation (2) into Equation (3) to get simultaneous equations.

$$
\begin{aligned}
& \pi_{D s 1}=\left(a-q_{s 1}-r q_{s 2}-\bar{t}+x_{s 1}-w_{s 1}\right) q_{s 1}-2 x_{s 1}^{2} \\
& \pi_{D s 2}=\left(a-q_{s 2}-r q_{s 1}-\bar{t}+x_{s 2}-w_{s 2}\right) q_{s 2}-2 x_{s 2}^{2}
\end{aligned}
$$

In order to know downstream firms' profit-maximizing outputs, we assume that the outputs of downstream firms have an impact on downstream firms' profits. The first-order conditions are given by

$$
\begin{aligned}
& \frac{\partial \pi_{D s 1}}{\partial q_{s 1}}=a-2 q_{s 1}-w_{s 1}+x_{s 1}-q_{s 2} \gamma-\bar{t}=0 \\
& \frac{\partial \pi_{D s 2}}{\partial q_{s 2}}=a-2 q_{s 2}-w_{s 2}+x_{s 2}-q_{s 1} \gamma-\bar{t}=0
\end{aligned}
$$

Using Equation (7) and Equation (8), we obtain optimal yield under the profit maximization. Then, downstream firms' outputs are as follows:

$$
\begin{aligned}
q_{s 1} & =-\frac{2 a-2 w_{s 1}+2 x_{s 1}-a \gamma+w_{s 2} \gamma-2 \bar{t}+\gamma \bar{t}}{-4+\gamma^{2}} \\
q_{s 2} & =-\frac{2 a-2 w_{s 2}+2 x_{s 2}-a \gamma+w_{s 1} \gamma-2 \bar{t}+\gamma \bar{t}}{-4+\gamma^{2}}
\end{aligned}
$$
increase effect can be expressed by the quadratic equation: $2 x_{s i}^{2}$. 
We assume the variation of downstream firms' outputs will affect profits for upstream firms, therefore, substituting
Equation (9) and Equation (10) into Equation (4), we can derive upstream firms' profits:

$$
\begin{aligned}
& \pi_{U s 1}=-\frac{w_{1}\left(2 a-2 w_{1}+2 x_{1}-a \gamma+w_{2} \gamma-x_{2} \gamma-2 \bar{t}+\gamma \bar{t}\right)}{-4+\gamma^{2}} \\
& \pi_{U s 2}=-\frac{w_{2}\left(2 a-2 w_{2}+2 x_{2}-a \gamma+w_{1} \gamma-x_{1} \gamma-2 \bar{t}+\gamma \bar{t}\right)}{-4+\gamma^{2}}
\end{aligned}
$$

Assuming upstream firms' profits be affected by upstream prices $w_{s i}$, using Equation (11) and Equation (12) to do the first-order conditions, can be written as. Using Equation
(13) and Equation (14), we obtain the cost of intermediate good $w_{s i}$ under the profit maximization.

$$
\begin{gathered}
\frac{\partial \pi_{U s 1}}{\partial w_{s 1}}=\frac{4 w_{s 1}-2 a-2 x_{s 1}+a \gamma-w_{s 2}+x_{s 2} \gamma+2 \bar{t}-\gamma \bar{t}}{-4+\gamma^{2}}=0 \\
\frac{\partial \pi_{U s 2}}{\partial w_{s 2}}=\frac{4 w_{s 2}-2 a-2 x_{s 2}+a \gamma-w_{s 1}+x_{s 1} \gamma+2 \bar{t}-\gamma \bar{t}}{-4+\gamma^{2}}=0 \\
w_{s 1}=-\frac{8 a+8 x_{s 1}-2 a \gamma-2 x_{s 2} \gamma-a \gamma^{2}-x_{s 1} \gamma^{2}-8 \bar{t}+2 \gamma \bar{t}+\gamma^{2} \bar{t}}{-16+\gamma^{2}} \\
w_{s 2}=-\frac{8 a+8 x_{s 2}-2 a \gamma-2 x_{s 1} \gamma-a \gamma^{2}-x_{s 2} \gamma^{2}-8 \bar{t}+2 \gamma \bar{t}+\gamma^{2} \bar{t}}{-16+\gamma^{2}}
\end{gathered}
$$

Besides, the variation of input goods price also determines downstream firms' R\&D spending. In order to gain optimal R\&D investment $x_{s i}$, we start by substituting upstream price $w_{s i}$ into Equation (9) and Equation (10). Further, putting the equilibrium outputs in Equation (5) and Equation (6) to get optimal profits from downstream firms. And finally, we assume that R\&D investment has an impact on profits. Using new profits formula to do the first-order conditions, the R\&D investment cost is given by

$$
x_{s 1}=x_{s 2}=\frac{2\left(-8+\gamma^{2}\right)(a-\bar{t})}{\delta}
$$

Let $\delta=\gamma^{6}-2 \gamma^{5}-28 \gamma^{4}+40 \gamma^{3}+222 \gamma^{2}-128 \gamma-496$. Using Equation (17) and Equation (18), downstream firms choose their R\&D investment, thereby determining the cost from intermediate goods

$$
x_{s 1}=x_{s 2}=\frac{\left(-16+\gamma^{2}\right)\left(-4+\gamma^{2}\right)^{2}(a-\bar{t})}{\delta}
$$

Substituting Equation (17) and Equation (18) back into the relevant functions yields the following equilibrium outputs. Profits of upstream firms turn out to be

$$
\pi_{U s 1}=\pi_{U s 2}=-\frac{2\left(-16+\gamma^{2}\right)^{2}\left(-4+\gamma^{2}\right)^{3}(a-\bar{t})^{2}}{\delta^{2}}
$$

Outputs of downstream firms turn out to be

$$
q_{s 1}=q_{s 2}=-\frac{2\left(-16+\gamma^{2}\right)\left(-4+\gamma^{2}\right)(a-\bar{t})}{\delta}
$$

Profits of downstream firms turn out to be

$$
\pi_{D s 1}=\pi_{D s 2}=\frac{4 \cdot A(a-\bar{t})^{2}}{\delta^{2}}
$$

Let $A=3968-2528 \gamma^{2}+526 \gamma^{4}-40 \gamma^{6}+\gamma^{8}$

Price of downstream firms turn out to be

$$
p_{s 1}=p_{s 2}=\frac{a \cdot B-2 \cdot E \bar{t}}{\delta}
$$

Let $B=-368+182 \gamma^{2}-26 \gamma^{4}+\gamma^{6}$ and $E=64+64 \gamma-$ $20 \gamma^{2}-20 \gamma^{3}+\gamma^{4}+\gamma^{5}$.

\section{Vertical Integration}

Let's assume that the downstream firm $D_{v 1}$ vertically integrates the upstream firm $U_{v 1}$. After this vertical integration, the cost of purchasing intermediate goods from $U_{v 1}$ will be zero, so $w_{v 1}=0$. This reflects the intuition that integrated firms obtain the input at marginal cost, avoiding double marginalization (Buehler \& Schmutzler, 2008) ${ }^{4}$. However, another upstream firm $\left(U_{v 2}\right)$ still needs to sell its intermediate goods to the downstream firm $\left(D_{v 2}\right)$ at the price $w_{v 2}$. Please see Figure 2 for the vertical integration

$4 \quad$ Salinger (1988) solution concept implies that the integrated firm is inactive in the upstream market, demonstrating that it does neither sell nor buy in the upstream market. Therefore, the separated downstream firm have to buy the input from the remaining separated upstream firm. 
framework. First of all, firms face a linear inverse demand curve.

$$
p_{v i}=a-q_{v i}-\gamma q_{v j}
$$

with $i \neq j, i, j=1,2,0 \leq \gamma \leq 1$.

Where $p_{v i}, q_{v i}, q_{v i}, a, \gamma$ have same definition with separation model. Both firms initially have identical transformation costs $\bar{t}>0$. Denoting firm i's efficiency improvement by $x_{s i}$, then ex post transformation costs are $\bar{t}-x_{s i}$. The separated downstream firm needs to use $w_{v 2}$ to purchase intermediate goods.

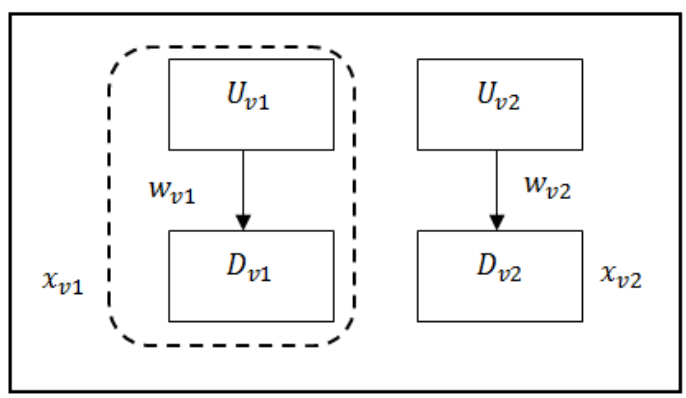

FIGURE 2. The structure of vertical integration

For the integrated firm, in turn, we have, as the marginal cost of producing the input is normalized to zero. Therefore, downstream firms' costs are thus given by

$$
\begin{gathered}
c_{D v 1}=\bar{t}-x_{v 1} \\
c_{D v 2}=\bar{t}-x_{v 2}+w_{v 2}
\end{gathered}
$$

Because $U_{v 1}$ and $D_{v 1}$ are merger together, the total profit of integrated firm is given by

$$
\pi_{I}=\left(p_{v 1}-c_{D v 1}\right) q_{v 1}-2 x_{v 1}^{2}
$$

The profit of separated downstream firm can be expressed as

$$
\pi_{D v 2}=\left(p_{v 2-C_{D v 2}}\right) q_{v 2}-2 x_{v 2}^{2}
$$

And lastly, the profit of separated upstream firm can be written as

$$
\pi_{U v 2}=w_{v 2} \times q_{v 2}
$$

Now, substituting Equation (23), Equation (24) and Equation (25) into Equation (26) and Equation (27) to get simultaneous equations.

$$
\begin{gathered}
\pi_{1}=\left(a-q_{v 1}-r q_{v 2}-\bar{t}+x_{v 1}\right) q_{v 1}-2 x_{v 1}^{2} \\
\pi_{D v 2}=\left(a-q_{v 2}-r q_{v 1}-\bar{t}+x_{v 2}\right) q_{v 2}-2 x_{v 2}^{2}
\end{gathered}
$$

In order to know downstream firms' profit-maximizing outputs, we assume that the outputs of the integrated firms and separated downstream firms have an impact on firms' profits. The first-order conditions are given by

$$
\frac{\partial \pi_{1}}{\partial q_{v 1}}=a-2 q_{v 1}+x_{v 1}-q_{v 2} \gamma-\bar{t}=0
$$

$$
\frac{\partial \pi_{D v 2}}{\partial q_{v 2}}=a-2 q_{v 2}-w_{v 2}+x_{v 2}-q_{v 1} \gamma-\bar{t}=0
$$

Using Equation (31) and Equation (32), we obtain optimal yield under the profit maximization. Then, integrated firm and separated downstream firm's outputs are as follows:

$$
\begin{gathered}
q_{v 1}=-\frac{2 a+2 x_{v 1}-a \gamma+w_{v 2} \gamma-x_{v 2} \gamma-2 \bar{t}+\gamma \bar{t}}{-4+\gamma^{2}} \\
q_{v 2}=-\frac{2 a+-2 w_{v 2}+2 x_{v 2}-a \gamma-x_{v 1} \gamma-2 \bar{t}+\gamma \bar{t}}{-4+\gamma^{2}}
\end{gathered}
$$

We assume the variation of outputs from separated downstream firm will affect profits for separated upstream firm. Thus, substituting Equation (32) into Equation (28), we can derive it's profits

$$
\pi_{U v 2}=-\frac{w_{v 2}\left(2 a-2 w_{v 2}+2 x_{v 2}-a \gamma-x_{v 1} \gamma-2 \bar{t}+\gamma \bar{t}\right)}{-4+\gamma^{2}}
$$

Assuming the profit of separated upstream firm be affected with separated upstream price $w_{v 2}$, using Equation (35) to make the first-order conditions. we can write as

$$
\frac{\partial \pi_{U v 2}}{\partial w_{v 2}}=\frac{4 w_{v 2}-2 a-2 x_{v 2}+a \gamma+x_{v 1} \gamma+2 \bar{t}-\gamma \bar{t}}{-4+\gamma^{2}}=0
$$

Using Equation (36), we obtain the cost from intermediate good $w_{v 2}$ and writing as

$$
w_{v 2}=\frac{1}{4}\left(2 x_{v 2}+2 a-\gamma a-x_{v 1} \gamma-2 \bar{t}+\gamma \bar{t}\right)
$$

In order to gain optimal R\&D investment $x_{v i}$, we start by substituting separated upstream price $w_{v 2}$ into Equation (33) and Equation (34). Further, putting the intermediate good price and equilibrium outputs into Equation (29) and Equation (30) to get optimal profits of the integrated firms and separated downstream firms. And lastly, we assume that R\&D investment has an impact on profits. Using new profits formula to do the first-order conditions, the R\&D investment cost is given by 


$$
\begin{gathered}
x_{v 1}=\frac{\left(-248+64 \gamma+127 \gamma^{2}-24 \gamma^{3}-20 \gamma^{4}+2 \gamma^{5}+\gamma^{6}\right)(a-\bar{t})}{-1736+1393 \gamma^{2}-364 \gamma^{4}+31 \gamma^{6}} \\
x_{v}=-\frac{56 a-32 a \gamma-15 a \gamma^{2}+8 a \gamma^{3}-56 \bar{t}+32 \gamma \bar{t}+15 \gamma^{2} \bar{t}-8 \gamma^{3} \bar{t}}{-1736+1393 \gamma^{2}-364 \gamma^{4}+31 \gamma^{6}}
\end{gathered}
$$

Using Equation (38) and Equation (39), separated downstream firm choose their R\&D investment, thereby determining the cost of intermediate goods

$$
w_{v 2}=-\frac{\left(-4+\gamma^{2}\right)^{2}\left(56-32 \gamma=15 \gamma^{2}+8 \gamma^{3}\right)(a-\bar{t})}{-1736+1393 \gamma^{2}-364 \gamma^{4}+31 \gamma^{6}}
$$

Substituting Equation (38), Equation (39) and Equation (40) back into the relevant functions yields the following equilibrium outputs. Because the equations are too lengthy, we are using a sign to simplify our formula. Let

$$
\begin{gathered}
\theta=\gamma^{2}-4, \eta=8 \gamma^{3}-15 \gamma^{2}-32 \gamma+56 \\
\rho=31 \gamma^{6}-364 \gamma^{4}+1393 \gamma^{2}-1736 \\
\sigma=-744+192 \gamma+505 \gamma^{2}-104 \gamma^{3}-108 \gamma^{4}+14 \gamma^{5}+7 \gamma^{6} \\
\omega=-496-96 \gamma+444 \gamma^{2}+52 \gamma^{3}-128 \gamma^{4}-7 \gamma^{5}+12 \gamma^{6}
\end{gathered}
$$

and $\varphi=\gamma^{4}+2 \gamma^{3}-12 \gamma^{2}-8 \gamma+31$. Profit of separated upstream firm turns out to be

$$
\pi_{U v 2}=-\frac{2 \theta^{3}(\eta)^{2}(a-\bar{t})^{2}}{(p \rho)^{2}}
$$

Output of integrated firm turn out to be

$$
q_{v 1}=\frac{8 \theta(\varphi)(a-\bar{t})}{\rho}
$$

Output of separated downstream firm turn out to be

$$
q_{v 2}=\frac{2 \theta(\eta)(a-\bar{t})}{\rho}
$$

Profit of integrated firm turn out to be

$$
\pi_{I}=\frac{2(\varphi)^{2}\left(448-240 \gamma^{2}+31 \gamma^{4}\right)(a-\bar{t})^{2}}{(-\rho)^{2}}
$$

Profit of separated downstream firm turn out to be

$$
\pi_{D v 2}=\frac{2(\eta)^{2}\left(31-16 \gamma^{2}+24 x \gamma^{4}\right)(a-\bar{t})^{2}}{(-\rho)^{2}}
$$

Price of integrated firm turn out to be

$$
p_{v 1}=\frac{a \cdot \sigma+2 \omega \cdot \bar{t}}{\rho}
$$

Price of separated downstream firm turn out to be

$$
p_{v 2}=a-\frac{2 \eta\left(-4+\gamma^{2}\right)(a-\bar{t})}{\rho}-\frac{8 \gamma \varphi\left(-4+\gamma^{2}\right)(a-\bar{t})}{\rho}
$$

\section{AUXILIARY RESULT}

In this section, we examine the change in outputs $(q)$, price $(p)$, profits $(\pi)$, intermediate goods' cost $(w), \mathrm{R} \& \mathrm{D}$ investment $\operatorname{cost}(x)$ and intimidation effect to analyze the problems to be encountered by firms in the future so as to select the optimal strategy for addressing the threat from competitors.

\section{Lemma 1. (Output)}

After the vertical integration, the outputs of integration firm $\left(q_{v 1}\right)$ will increase, and the outputs of separated firm $\left(q_{v 2}\right)$ will decrease, that is, $\left(q_{s 1}-q_{v 1}\right)<0$ and $\left(q_{s 2}-q_{v 2}\right)>0$.

\section{Proof}

We want to analysis the variation of outputs after the vertical integration. Thus, we use downstream separation firm $1\left(q_{s 1}\right)$ to minus integration firm $1\left(q_{v 1}\right)$ and downstream separation firm $2\left(q_{s 2}\right)$ to minus integration firm $2\left(q_{v 2}\right)$. Because the equation is too lengthy, we are using a sign to simplify.

Let $\theta=\gamma^{2}-4$ and $\delta=\gamma^{6}-2 \gamma^{5}-28 \gamma^{4}+40 \gamma^{3}+222 \gamma^{2}-$ $128 \gamma-496$ The difference of output between $q_{s 1}$ and $q_{v 1}$, we can express as

$$
\left(q_{s 1}-q_{v 1}\right)=2 \theta\left(\frac{16-\gamma^{2}}{\delta}-\frac{4 \varphi}{\rho}\right)(a-\bar{t})
$$

If product substitutability $(\gamma)$ is no less than zero and no more than one $(0 \leq \gamma \leq 1)$, the term is negative. Please see Figure 3. Because $a>\bar{t}$ then $(a>\bar{t})>0$. Using this concept substituting into Equation (48), we obtain

$$
\left(q_{s 1}-q_{v 1}\right)=2 \theta\left(\frac{16-\gamma^{2}}{\delta}-\frac{4 \varphi}{\rho}\right)(a-\bar{t})<0
$$

The difference of output between $q_{s 2}$ and $q_{v 2}$, we can express as

$$
\left(q_{s 2}-q_{v 2}\right)=2 \theta\left(\frac{16-\gamma^{2}}{\delta}-\frac{\eta}{\rho}\right)(a-\bar{t})
$$

If product substitutability $(\gamma)$ is no less than zero and no more than one $(0 \leq \gamma \leq 1)$, the term $\theta\left(16-\gamma^{2} / \delta-\eta / \rho\right)$ is positive. Please see Figure 4.

Because $a>\bar{t}$, then $(a>\bar{t})>0$. Using this concept substituting into Equation (50), we obtain

$$
\left(q_{s 2}-q_{v 2}\right)=2 \theta\left(\frac{16-\gamma^{2}}{\delta}-\frac{\eta}{\rho}\right)(a-\bar{t})>0
$$




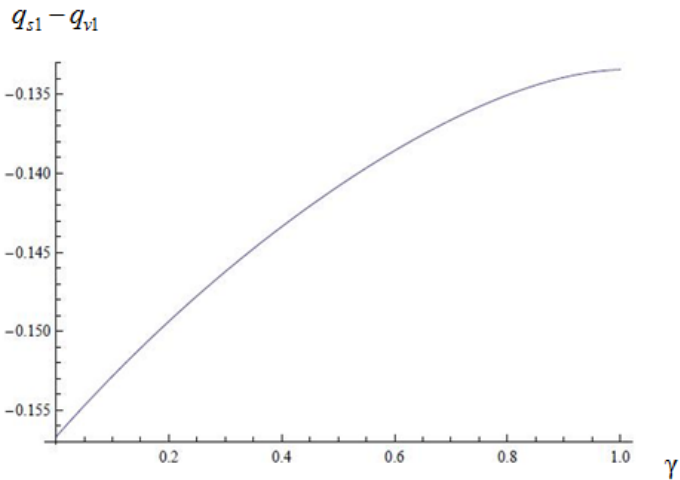

FIGURE 3. The impact of product substitutability for $\left(q_{s 1}-q_{v 1}\right)$.

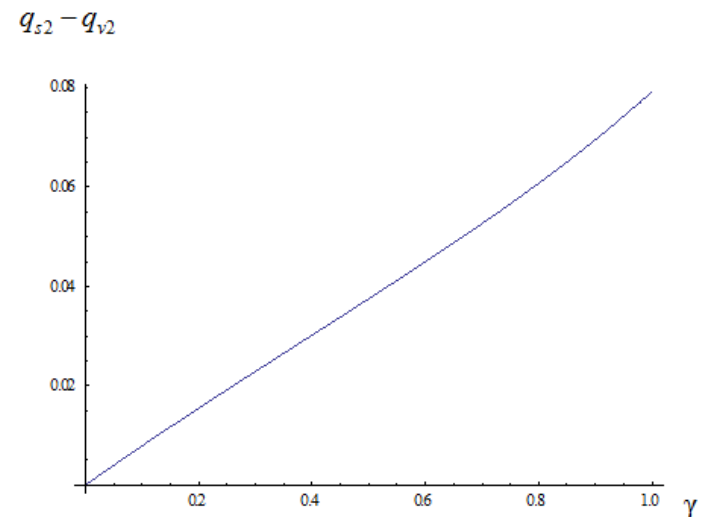

FIGURE 4. The impact of product substitutability for $\left(q_{s 2}-q_{v 2}\right)$.

As can be seen from the above proof, $\left(q_{s 2}-q_{v 2}\right)<0$ represents the outputs of integrated firm will increase after the vertical integration; and Figure 3 shows that the larger the product substitutability $(\gamma)$, the greater the increase in outputs; on the contrary, the firm conducting no vertical integration will see the decrease in outputs; and Figure 4 show that the larger the product substitutability $(\gamma)$, the greater the decrease in outputs.

\section{Lemma 2 (Price)}

After the vertical integration, the price $\left(p_{v 1}\right)$ of firm conducting vertical integration will decrease, and the price ( $\left.p_{v 2}\right)$ of separated firm will decrease too, that is, $\left(p_{s 1}-p_{v 1}\right)>$ 0 and $\left(p_{s 2}-p_{v 2}\right)>0$.

\section{Proof}

We want to analysis the variation of price after the vertical integration. Thus, we use downstream separation firm $1\left(p_{s 1}\right)$ to minus integration firm $1\left(p_{v 1}\right)$ and downstream separation firm $2\left(p_{s 2}\right)$ to minus integration firm $2\left(p_{v 2}\right)$. Because the equation is too lengthy, we using sign to simplify.

Let

$$
F=134912-194176 \gamma^{2}+96 \gamma^{3}+1125564 \gamma^{4}
$$

$$
-52 \gamma^{5}-33471 \gamma^{6}+7 \gamma^{7}+5324 \gamma^{8}-419 \gamma^{1} 0+12 \gamma^{1} 2
$$

The difference of price between $p_{s 1}$ and $p_{v 1}$, we can express as

$$
\left(p_{s 1}-p_{v 1}\right)=\frac{2 F}{\delta \rho}(a-\bar{t})
$$

$$
p_{s 1}-p_{v 1}
$$

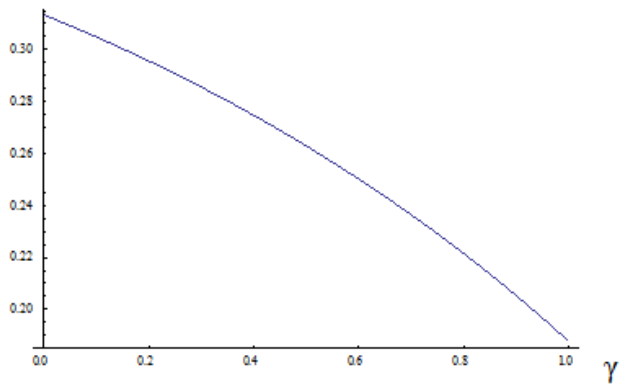

FIGURE 5. The impact of product substitutability for $\left(p_{s 1}-p_{v 1}\right)$

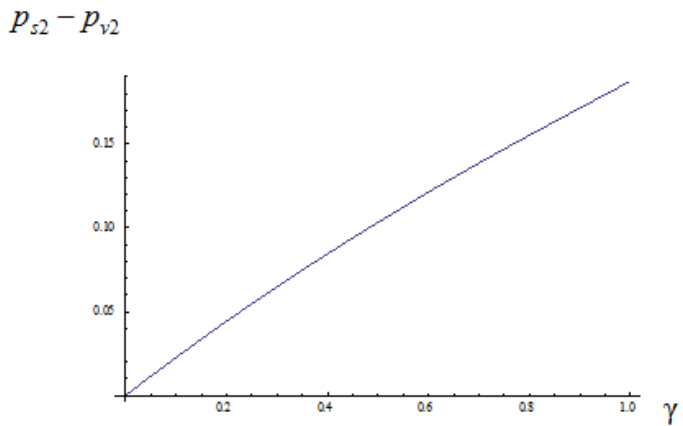

FIGURE 6. The impact of product substitutability for $\left(p_{s 2}-p_{v 2}\right)$

If product substitutability $(\gamma)$ is no less than zero and no more than one $(0 \leq \gamma \leq 1)$, the term. Please see Figure 5 . Because $a>\bar{t}$, then $(a>\bar{t})>0$. Using this concept substituting into Equation (52), we obtain

$$
\left(p_{s 1}-p_{v 1}\right)=\frac{2 F}{\delta \rho}(a-\bar{t})>0
$$

The difference of price between $p_{s 2}$ and $p_{v 2}$, we can express as

$$
\left(p_{s 2}-p_{v 2}\right)=\frac{2 \gamma G}{\delta \rho}(a-\bar{t})
$$

Let.

$$
\begin{aligned}
& G=100096+224 \gamma+123008 \gamma^{2}-224 \gamma^{3}+261452 \gamma^{4} \\
& +79 \gamma^{5}-15855 \gamma^{6}-8 \gamma^{7}+2202 \gamma^{8}-153 \gamma^{10}+4 \gamma^{12}
\end{aligned}
$$

If product substitutability $(\gamma)$ is no less than zero and no more than one $(0 \leq \gamma \leq 1)$, the term $2 \gamma G / \delta \rho>0$. Please see Figure 6.

Because $a>\bar{t}$, then $(a>\bar{t})>0$. Using this concept substituting into Equation (54), we obtain

$$
\left(p_{s 2}-p_{v 2}\right)=\frac{2 \gamma G}{\delta \rho}(a-\bar{t})>0
$$


As can be seen from the above proof, $\left(p_{s 1}-p_{v 1}\right)>0$ represents the price of integrated firm will decrease after the vertical integration; and Figure 5 shows that the larger the product substitutability $(\gamma)$, the greater the decrease in price; the firm conducting no vertical integration will also see the decrease in price; and Figure 6 show that the larger the product substitutability $(\gamma)$, the greater the decrease in price.

\section{Lemma 3 (R\&D Investment and Intimidation Effect)}

After the vertical integration, the investment cost $\left(x_{v 1}\right)$ of firm conducting vertical integration will increase and the investment cost $\left(x_{v 2}\right)$ of separated firm will decrease, that is, $\left(x_{s 1}-x_{v 1}\right)<0$ and $\left(x_{s 2}-x_{v 2}\right)<0$. Integrated firm has intimidation effect.

\section{Proof}

We want to analysis the variation of investment cost after the vertical integration. Thus, we use downstream separation firm $1\left(x_{s 1}\right)$ to minus integration firm $1\left(x_{v 1}\right)$ and downstream separation firm $2\left(x_{s 2}\right)$ to minus integration firm $2\left(x_{v 2}\right)$. Because the equation is too lengthy, we using sign to simplify.

Let

$$
H=\gamma^{6}+2 \gamma^{5}-20 \gamma^{4}-24 \gamma^{3}+127 \gamma^{2}+64 \gamma-240
$$

The difference in investment cost between $x_{s 1}$ and $x_{v 1}$, we can express as

$$
\left(x_{s 1}-x_{v 1}\right)=\left(\frac{2 \gamma^{2}-16}{\delta}\right)-\left(\frac{H}{\rho}\right)(a-\bar{t})
$$

If product substitutability $(\gamma)$ is no less than zero and no more than one $(0 \leq \gamma \leq 1)$, the term $\left(2 \gamma^{2}-16 / \delta\right)-$ $(H / \rho)<0$. Please see Figure 7. Because $a>\bar{t}$, then $(a>\bar{t}$ ) $>0$. Using this concept substituting into Equation (56), we obtain

$$
\left(x_{s 1}-x_{v 1}\right)=\left(\frac{2 \gamma^{2}-16}{\delta}\right)-\frac{H}{\rho}(a-\bar{t})<0
$$

The difference of investment cost between $x_{s 2}$ and $x_{v 2}$, we can express as

$$
\left(x_{s 2}-x_{v 2}\right)=\left(\frac{J \cdot \gamma(2+\gamma)^{2}}{\delta . \rho}\right)(a-\bar{t})
$$

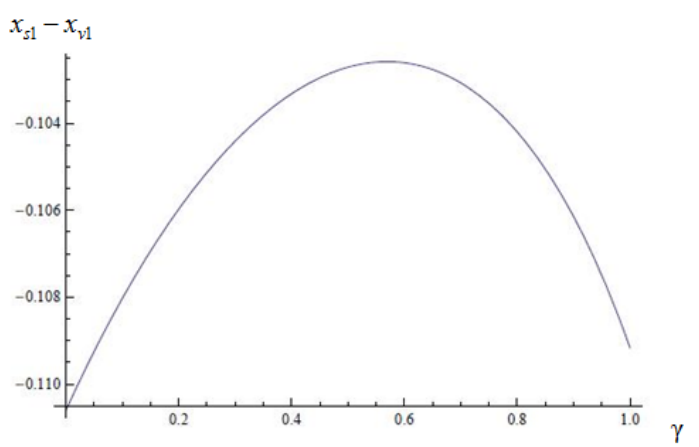

FIGURE 7. The impact of product substitutability for $\left(x_{s 1}-x_{v 1}\right)$

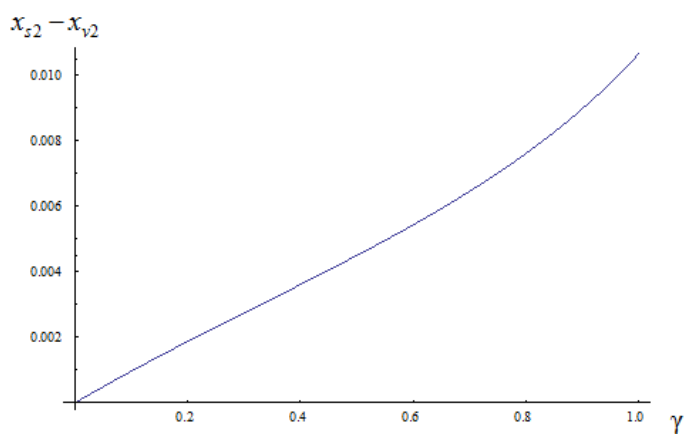

FIGURE 8. The impact of product substitutability for $\left(x_{s 2}-x_{v 2}\right)$

Let

$$
J=2176-2624 \gamma+352 \gamma^{2}+656 \gamma^{3}-254 \gamma^{4}-\gamma^{5}+8 \gamma^{6}
$$

If product substitutability $(\gamma)$ is no less than zero and no more than one $(0 \leq \gamma \leq 1)$, the term. Please see Figure 8 . Because $a>\bar{t}$, then $(a>\bar{t})>0$. Using this concept substituting into Equation (58), we obtain

$$
\left(x_{s 2}-x_{v 2}\right)=\left(\frac{J \cdot \gamma(2+\gamma)^{2}}{\delta . \rho}\right)(a-\bar{t})>0
$$

As can be seen from the above proof and Figure 7, the R\&D expenditure of firm conducting vertical integration will increase after the vertical integration. However, the capital invested into R\&D by the integrated firm will increase when the product substitutability $(\gamma)$ is less than 0.6 , but when the product substitutability $(\gamma)$ is more than 0.6 , the ratio of R\&D investment will decrease progressively; this shows that the integrated firm is willing to make more R\&D investment when the product substitutability $(\gamma)$ is approaching certain limit, but when $\gamma$ passes this limit, the integrated firm's willingness to make R\&D investment will decrease progressively. For the firms conducting no vertical integration, their R\&D investment will decrease. As is shown in Figure 8 , the larger the product substitutability $(\gamma)$, the greater the decrease in $R \& D$ investment by the firm conducting no integration. Thus, it can be seen that the firm conducting integration has an intimidation effect on those not doing so. 


\section{Economic Impact Analysis}

In this section, we will compare the economic benefits of vertical integration strategy with those of non-M\&A strategy. The economic benefit defined here refers to the profit maximization $(\pi)$ pursued by firms, and this paper also discusses the effect of the market size $(a)$ and product substitutability $(\gamma)$ on economic benefits before and after the vertical integration.

\section{Lemma 4 (Profit)}

When the downstream firm $\left(D_{v} 1\right)$ vertically integrates the upstream firm $\left(U_{v} 1\right)$, but the upstream firm $\left(U_{v} 2\right)$ and the downstream firm $\left(D_{v} 2\right)$ remain independent, the total profit $(\pi I)$ of the vertically integrated firm will be greater than the sum of the respective profit of the upstream and downstream firm before integration $\left(\pi T=\pi U_{s 1}+\pi D_{s 1}\right)$, that it, $\pi I>\pi T$.

\section{Proof}

We want to analysis the variation of profit after the vertical integration. Thus, we use integration firm $1(\pi I)$ to minus separation firm $1(\pi T)$. Because the equation is too lengthy, we are using a sign to simplify.

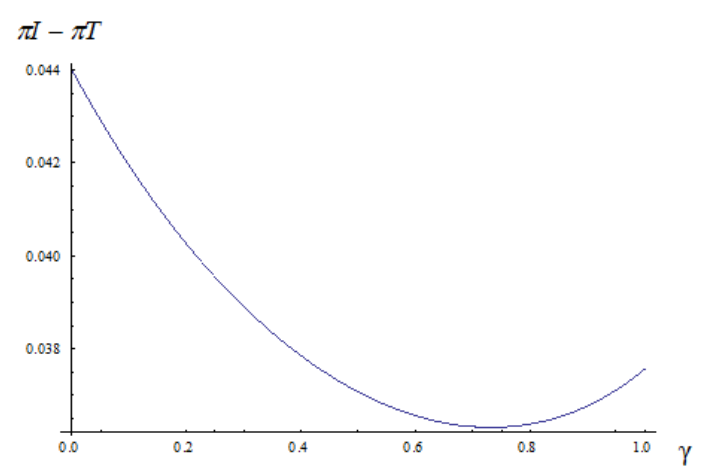

FIGURE 9. The impact of product substitutability for $(\pi I-\pi T)$

Let

$L=31 \gamma^{4}-240 \gamma^{2}+448$ and

$$
M=\gamma^{10}-46 \gamma^{8}+768 \gamma^{6}-5724 \gamma^{4}+19392 \gamma^{2}-24320
$$

. The difference of profit between $\pi I$ and $\pi T$, we can express as

$$
(\pi I-\pi T)=2\left(\frac{\varphi^{2} L}{(-\rho)^{2}}+\frac{M}{\delta^{2}}\right)(a-\bar{t})^{2}
$$

If product substitutability $(\gamma)$ is no less than zero and no more than one $(0 \leq \gamma \leq 1)$, the term $\varphi^{2} L /(-\rho)^{2}+M / \delta^{2}>$ 0 . Please see Figure 9. Because $(a-\bar{t})>0$, then $(a-\bar{t})^{2}>0$ Using this concept substituting into Equation (60), we obtain

$$
(\pi I-\pi T)=2\left(\frac{\varphi^{2} L}{(-\rho)^{2}}+\frac{M}{\delta^{2}}\right)(a-\bar{t})^{2}>0
$$

As can be seen from the above proof, $(\pi I-\pi T)>0$, namely, the profit after vertical integration is greater than the total profits of both upstream and downstream firm before the integration. Figure 9 shows that when the product substitutability $(\gamma)$ approaches 0 , the result of $(\pi I-\pi T)$ is the largest. So, for the benefits of vertical integration, the smaller the product substitutability $(\gamma)$, the larger the product differentiation, which in turn means the larger benefit after integration.

\section{Lemma 5 (Market Size)}

When the market size expands, the profit difference between the vertically integrated firm and that without any integration will grow, namely $\partial(\pi I-\pi T) / \partial a>0$.

\section{Proof}

We want to analysis the impact of market size on profit after integration. Thus, we doing the first-order conditions:

$$
\frac{\partial(\pi I-\pi T)}{\partial a}=4\left(\frac{L \varphi^{2}}{-\rho^{2}}+\frac{M}{\delta^{2}}\right)(a-\bar{t})
$$

The term $L \varphi^{2} /(-r h o)^{2}+M / \delta^{2}>0$. It's the same with Figure 9. Because $a>\bar{t}$, then $(a>\bar{t})>0$. Using this concept substituting into Equation (62), we obtain

$$
\frac{\partial(\pi I-\pi T)}{\partial a}=4\left(\frac{L \varphi^{2}}{-\rho^{2}}+\frac{M}{\delta^{2}}\right)(a-\bar{t})>0
$$

As can be seen from the above proof:

The larger the market size $(a)$ after vertical integration, the greater the profit difference between the firm conducing and not conducting vertical integration $(\pi I-\pi T)$.

2. As with the result of proposition 6 , the more the product substitutability $(\gamma)$ approaches 0 , the larger the result of $(\pi I-\pi T)$ will be. That means the smaller the product substitutability $(\gamma)$, the larger the product differentiation, which in turn means the larger benefit after integration.

\section{Lemma 6 (Product Substitutability)}

When the product substitutability $(\gamma)$ grows, the profit difference between the vertically integrated firm and that without any integration may increase or decrease, namely $\partial(\pi I-\pi T) / \partial \gamma>0$.

\section{Proof}

We want to analysis the impact of product substitutability $(\gamma)$ with the profit of integration firm. Thus, we doing the first-order conditions: 


$$
\frac{\partial(\pi I-\pi T)}{\partial \gamma}=4\left(\frac{4 \gamma \varphi^{2}\left(31 \gamma^{2}-100\right)}{(-\rho)^{2}}+\frac{4 \varphi L . R}{(-\rho)^{2}}-\frac{4 \gamma \varphi^{2} L . S}{\rho^{3}}+\frac{2 \gamma . V}{\delta^{2}}-\frac{4 M . Y}{\delta^{3}}\right)(a-\bar{t})^{2}
$$

Let $R=2 \gamma^{3}+3 \gamma^{2}-12 \gamma-4$,

$$
\begin{gathered}
S=93 \gamma^{4}-728 \gamma^{2} 1393 \\
V=5 \gamma^{8}-184 \gamma^{6}+2304 \gamma^{4}-11448 \gamma^{2}+19392 \text { and } \\
Y=3 \gamma^{5}-5 \gamma^{4}-56 \gamma^{3}+60 \gamma^{2}+222 \gamma-64
\end{gathered}
$$

If product substitutability $(\gamma)$ is no less than zero and no more than one $(0 \leq \gamma \leq 1)$, the value of

$$
\begin{gathered}
4 \gamma \varphi^{2}\left(31 \gamma^{2}-120\right) /(-\rho)^{2}+4 \varphi L . R /-\rho^{2} \\
-4 \gamma \varphi^{2} L . S / \rho^{3}+2 \gamma . V / \delta^{2}-4 M . Y / \delta^{3}
\end{gathered}
$$

between $-.017 \sim 0.010$. Please see Figure 10. Because $(a-\bar{t})>0$, then $(a-\bar{t})^{2}>0$. Using this concept substituting into Equation (64), we obtain

$$
\frac{\partial(\pi I-\pi T)}{\partial \gamma}
$$

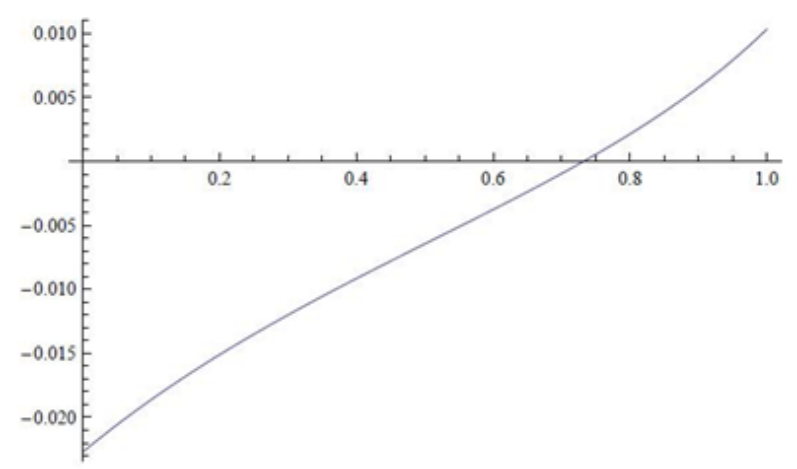

FIGURE 10. The impact of product substitutability for $\frac{\partial(\pi I-\pi T)}{\partial \gamma}$

$$
\frac{\partial(\pi I-\pi T)}{\partial \gamma}=4\left(\frac{4 \gamma \varphi^{2}\left(31 \gamma^{2}-120\right)}{(-\rho)^{2}}+\frac{4 \varphi L . R}{(-\rho)^{2}}-\frac{4 \gamma \varphi^{2} L . S}{\rho^{3}}+\frac{2 \gamma . V}{\delta^{2}}-\frac{4 M . Y}{\delta^{3}}\right)(a-\bar{t})^{2}
$$

The value between $-0.017 \sim 0.010$. As can be seen from the above proof, when the product substitutability $(\gamma)$ grows, the profit difference may increase or decrease. When the product substitutability $(\gamma)$ goes from 0 to 1 , the profit difference will first decrease, but when $\gamma$ reaches and goes beyond about 0.74 , the profit difference will increase. This result also echoes in Figure 9.

\section{CONCLUSION}

In this paper, we analyze the implication of research results on the firms' M\&A strategy. When the downstream firm carries out the upward integration, the integration firm will enjoy the zero cost of intermediate good relatively. Therefore the double marginalization is removed. In this case, more consumers will buy products from $D_{v 1}$ to avoid the secondary exploitation, which in turn will drive the increase in output of integrated firm and generate more profits than before integration. When the market size $(a)$ grows up, the integration firm will reduce its cost due to economies of scale and offer the more competitive price, and bring more and more profits to the integration firm. More importantly, when the product substitutability $(\gamma)$ is extremely large or small, the integration firm will reduce its cost due to economies of scale. On the other hand, integration firm enjoy the product premium thanks to the product substitutability, and the profit difference will also get larger accordingly. Additionally, the integrated firm will cause an intimidation effect on its competitors, and such integrated firm will increase its $R \& D$ investment and reduce the R\&D investment of its competitors, therefore enjoying more profits. However, when the competitor's competitiveness decreases to a certain level or the competitor exits market, the vertically integrated firm will begin to reduce its R\&D expenditure due to the lack of competitors.

According to the above research results, we give the following specific methods for deciding on whether to carry out M\&A strategy and which M\&A mode to choose:

(1) For an industry where there are R\&D activities in the downstream side, the firm conducting vertical integration will achieve higher economic benefits than before integration. That means, the firm, after M\&A, will get a better market position and more profits due to the expansion of production scale, growth of market share, integration of upstream and downstream resources, and removal of double marginalization. In addition, the integrated firm will use its R\&D ability to realize the product premium or take advantages of technology transfer to reduce costs, therefore achieving the comprehensive benefits based on revenues. Therefore, M\&A is an effective strategy for firms to pursue sustainable growth.

(2) In order to realize the maximum comprehensive benefits after M\&A, the firms which want to carrying out M\&A need to consider its competitor's product substitutability (product differentiation). For the individual integration 
strategies, the product substitutability, whatever becoming larger or smaller, will help to increase the profits after vertical integration. For example, the products in solar energy sector feature larger substitutability. The layout of SAS is going to the complete vertical integration. It acquired Sunrise Global Solar Energy in 2014, and then acquired German aleo solar energy company, which not only enables this SAS to obtain the relevant equipment and raw materials, but also get the production technologies, trademarks and patents. The complete industrial chain significantly increased SAS's profit and set a higher entry barrier for com- petitors.

\section{IMPLICATIONS}

According to the research results, as the market size grows, M\&A will offer more benefits. Therefore, in the long run, the early adoption of M\&A strategies will lead to better economic benefits to firms from such industries as will see the scale expansion and more demands in the future; it also can help firms to make consideration and planning in advance for whether to expand scale. Chinese Mainland is fostering local companies through active international M\&A and this is the best example.

\section{REFERENCES}

Al-Barashdi, S. (2016). The efficiency of alternative dispute resolutions in the oil and gas industry. International Journal of Business and Administrative Studies, 2(1), 20-23. doi:https://doi.org/10.20469/ijbas.10006-2

Buehler, S., \& Schmutzler, A. (2005). Asymmetric vertical integration. Advances in Theoretical Economics, 5(1), 34-50. doi:https://doi.org/10.2202/1534-5963.1164

Buehler, S., \& Schmutzler, A. (2008). Intimidating competitors: Endogenous vertical integration and downstream investment in successive oligopoly. International Journal of Industrial Organization, 26(1), 247-265. doi:https://doi.org/10.1016/ j.ijindorg.2006.11.005

Chen, Y. (2001). On vertical mergers and their competitive effects. Rand Journal of Economics, 32(4), 667-685. doi:https:// doi.org/10.2307/2696387

Chen, Y. C. (2014). The effect of business groups on M\&A performance, advanced master business administration (Unpublished master thesis). National Cheng Kung University, Tainan, Taiwan.

Coase, R. H. (1937). The nature of the firm. Economica, 4(16), 386-405. doi:https://doi.org/10.1111/j.1468-0335.1937 .tb00002.x

D'Aspremont, C., \& Jacquemin, A. (1988). Cooperative and noncooperative R\&D in duopoly with spillovers. The American Economic Review, 78(5), 1133-1137.

Greenhut, M. L., \& Ohta, H. (1979). Vertical integration of successive oligopolists. The American Economic Review, 69(1), 137-141. doi:https://doi.org/10.2307/1057004

Hamel, G., \& Getz, G. (2008). Funding growth in an age of austerity. Taipei, Taiwan: Commonwealth Publishing Company Press.

Hart, O., Tirole, J., Carlton, D. W., \& Williamson, O. E. (1990). Vertical integration and market foreclosure. Brookings Economic Activity Microeconomics, 1990, 205-286. doi:https://doi.org/10.2307/2534783

Huang, S. Y. (2008). The economic effect comparison of vertical integration and horizontal integration: Two firms in upstream and two firms in downstream model (Unpublished master's thesis). Department of International Bussiness, Tunghai University, Taichung, Taiwan.

Li, C. F. (2008). The comparison of economic efficiency between vertical integration and horizontal integration on upstream firms: A model of four upstreams and two downstreams (Tech. Rep.). Department of International Bussiness. Tunghai University, Taichung, Taiwan.

Lin, C. Y. (2010). The study of pre-merger valuation and management based on a computer company's case (Unpublished master's thesis). National Chengchi University, Taipei, Taiwan.

Lin, J. R., Hsieh, T. L., Hsu, C. S., Huang, S. Y., \& Liu, H. L. (2010). Merger and acquisitions and innovation activity: The application of matching approach and count data model. In Paper Presented at the, Eleventh Annual Conference on Empirical Economics, Department of Economics \& Graduate of International Economics, National Chung Cheng University, Chiayi, Taiwan.

Lin, S. H. (2013). Case study on the first merger in Taiwan solar energy industry (Technical report). Institute of Finance, National Chiao Tung University, Hsinchu, Taiwan. 
Milliou, C. (2004). Vertical integration and R\&D information flow: Is there a need for 'firewalls'? International Journal of Industrial Organization, 22(1), 25-43. doi:https://doi.org/10.1016/s0167-7187(03)00090-0

Milliou, C., \& Pavlou, A. (2013). Upstream mergers, downstream competition, and R\&D investments. Journal of Economics \& Management Strategy, 22(4), 787-809. doi:https://doi.org/10.1111/jems.12034

Ordover, J. A., Saloner, G., \& Salop, S. C. (1990). Equilibrium vertical foreclosure. The American Economic Review, 91(3), 127-142. doi:https://doi.org/10.1257/aer.91.3.428

Piyachat, B. (2017). The relationships among resources' commitment reverse logistics innovation reverse logistics performance and reverse logistics cost savings: Manufacturing vs service industry. Journal of Administrative and Business Studies, 3(3), 122-135. doi:https://doi.org/10.20474/jabs-3.3.2

Salinger, M. A. (1988). Vertical mergers and market foreclosure. The Quarterly Journal of Economics, 103(2), 345-356. doi:https://doi.org/10.2307/1885117

Silva, H. M. S. V., \& Madushani, R. A. I. (2017). The impact of human resource competencies of front line employees on tourist arrivals of unclassified hotels in Western Province, Sri Lanka. Journal of Advanced Research in Social Sciences and Humanities, 2(1), 9-16. doi:https://doi.org/10.26500/jarssh-02-2017-0102

Sun, M. J. (2000). A study of performance impact on domestic public companies' M\&A activity (Unpublished master's thesis). Department of Business Administration, National Chengchi University, Taipei, Taiwan.

Yang, S. L. (2013). Can merger really develop synergy? An example from Yuanto securitites merger polaris securitites (Unpublished master's thesis). National Chengchi University, Taipei, Taiwan. 